\title{
Influence of Cytokine gene polymorphisms on pro-/anti-inflammatory cytokine imbalance in Premature Coronary Artery Disease
}

\author{
ANSARI, WM ${ }^{1}$; HUMPHRIES, SE ${ }^{2}$; NAVEED, $\mathrm{AK}^{3}$; KHAN, OJ ${ }^{4}$; KHAN, DA ${ }^{4}$;
}

${ }^{1}$ Army Medical College, National University of Science and Technology

(NUST), Islamabad, Pakistan.

${ }^{2}{ }^{4}$ Cardiovascular Genetics Institute, UCL, UK

${ }^{3}$ Riphah International University, Rawalpindi, Pakistan

${ }^{3}$ Azad Jammu \& Kashmir Medical College, Muzaffarabad.

DR.WAFA MUNIR ANSARI

Department of Chemical Pathology, Army Medical College, National University of Sciences and Technology, Sector H-12, Islamabad, Pakistan.

wafamuniransari@yahoo.com

PROF.STEVE E HUMPHRIES,

Cardiovascular Genetics Institute, University College London, United Kingdom.

steve.humphries@ucl.ac.uk

OMER JAMSHED KHAN

Azad Jammu \& Kashmir Medical College, Muzaffarabad.

omerjkhan@gmail.com

PROF.DR.ABDUL KHALIQ NAVEED

Dean RARE

Riphah International University, Peshawar Road, Rawalpindi, Pakistan

khaliq.naveed@riphah.edu.pk

Corresponding Author: Dr.Wafa Munir Ansari,

Department of Chemical Pathology, Army Medical College, National University of Science and Technology (NUST), Islamabad, Pakistan. 
E mail: wafaomeransari@gmail.com ,Telephone No.92-03215505342

Key words: Premature Coronary Artery Disease; Single Nucleotide Polymorphisms; Cytokine imbalance; Cytokine levels.

Word Count: 3081

\section{ABSTRACT}

Background: Premature coronary artery disease (PCAD) has taken the form of an epidemic in developing countries like Pakistan. Genetic information has the potential to create a more personalised, prompt, early and accurate risk evaluation. Moreover, the effect of these genetic variants on the serum biomarker levels (phenotype) needs to be studied to assess their potential causal role in the pathogenesis of PCAD. Objectives were to determine the genotypic distribution of $I L-18, T N F-a l p h a, I L-6$ and $I L-10$ single nucleotide polymorphisms (SNPs) in Pakistani PCAD cases and disease free controls and to study the effect of these gene polymorphisms on the serum cytokine levels (IL-18,TNF-alpha,IL-6 and IL-10) and cytokine imbalance (IL-18:IL-10 \& TNF-alpha:IL-10). Material and Methods: The case-control study was carried out in Army Medical College, National University of Sciences and Technology, Islamabad in collaboration with the Cardiovascular Genetics Institute, University College London, UK. Subjects $(\mathrm{n}=340)$ with $>70 \%$ stenosis in at least a single major coronary artery on angiography were taken as PCAD cases along with 310 angiographically verified controls. ELISA was performed for measuring the concentrations of serum IL-18, TNF-alpha, IL-6 and IL-10. Genotyping was done using TAQMAN assay. Results: The risk allele frequencies (RAF) of rs1800795 (IL-6) and rs 187238 (IL-18) cytokine gene promoter SNPs were significantly higher in the PCAD cases as compared to the controls. Serum IL-18 and IL-10 levels were significantly greater in the IL-18 rs 187238 GG genotype patients while serum IL-18 and IL-6 levels were significantly 
higher in patients having the IL-6 rs 1800795 CC genotype. IL-18 SNP rs 1946519 significantly altered the IL-18, TNF-alpha, IL-6, IL-18/IL-10 and TNF-alpha/IL-10 ratio levels followed by TNF-alpha SNP rs 1800629 which significantly altered the serum levels of IL-18, IL-18:IL-0 and TNF-alpha:IL-10 ratios. Conclusion: The association of the above mentioned SNPs with differential serum cytokine levels especially the pro-/antiinflammatory cytokine imbalance points towards their potential causal role in the immune inflammatory pathogenic pathway of PCAD.

Key words: Premature Coronary Artery Disease; Single Nucleotide Polymorphisms; Cytokine imbalance; Cytokine levels. 


\section{INTRODUCTION:}

Premature CAD is characterized by $>70 \%$ blockade in at least one major vessel as seen on coronary angiography in patients $\leq 45$ years of age (Dhillon et al., 2004). It is the leading cause of morbidity and mortality in young males and females (Rosamond et al., 2007). PCAD occurs almost a decade earlier in the South Asian population as compared to the West (Aggarwal et al., 2014). It is estimated that by the year 2030 the cause of death in 23.3 million people annually will be Coronary Artery Disease (Vilahur et al., 2014). Cytokines are small proteins which are mainly released as a response of the host to disease or infection. A number of pro-inflammatory and anti-inflammatory cytokines have been identified in the pathogenesis of PCAD and this inflammatory cascade has a role in maintaining a delicate balance between various factors that monitor the integrity of the vascular system (Kaptoge et al., 2014). Cytokine imbalance and its role in the acceleration of atherosclerosis has been highlighted (Khan et al., 2011). Autieri et al., 2012 showed IL18:IL-10 can independently predict adverse events in coronary artery disease patients. Li et al., 2014 demonstrated that IL-18:IL-10 ratio can also predict CVS events in stable CAD patients. IL-18:IL-10 ratio has a vital role in formation of atherosclerotic arterial lesions 
(Xiao-Feng et al.,2009). Patients with CAD demonstrated higher values of TNF-alpha:IL-10 than the controls (Wojciech et al.,2008).Kaur et al.,2006 suggests that the balance between IL-10:TNF-alpha is of more functional significance in cardiac injury. The effect of the cytokine genetic variants on the serum biomarker levels (phenotype) need to be studied to assess their potential causal role in the pathogenesis of PCAD. While certain studies have shown that the cytokine SNPs can lead to alteration in the inflammatory response in CAD (Satti et al., 2013) others have negated it (Cho et al., 2013). Thus, a controversy still exists regarding the influence of these cytokine gene promoter polymorphisms on the serum cytokine levels particularly in the high risk Pakistani subjects. Hence, objectives were to determine the genotypic distribution of pro-inflammatory IL-18 (rs1946519 and rs187238), TNF-alpha (rs 1800629),IL-6 (rs 1800795) and anti-inflammatory IL-10 (rs1800871) gene promoter SNPs in PCAD patients and disease free controls and to determine the differential serum cytokine levels (IL-18,IL-10,IL-6, TNF-alpha, IL-18:IL-10 \& TNF-alpha:IL-10 ratios) with respect to the genotypic distribution of the selected SNPs in PCAD patients and controls.

\section{Material and Methods:}

The case-control study was conducted in the Chemical Pathology department Army Medical College, National University of Sciences and Technology (NUST) Rawalpindi, Pakistan, in collaboration with Cardiovascular Genetics (CVG) Institute, University College London (UCL), London, United Kingdom (UK) after approval by the Institutional Ethical review commitees. A total of 650 subjects aged $\leq 45$ years who were stable and were due to undergo coronary angiography were consecutively recruited from Armed Forces Institute of Cardiology (AFIC) Rawalpindi. The participants had a recent history ( $<2$ months) of an 
episode of left sided chest pain and were advised angiography by consultant cardiologists after evaluation. All participants were citizens of Pakistan. The sampling technique was nonprobability convenience sampling. 340 subjects who displayed $>70 \%$ stenosis in one coronary artery on angiography were categorized as Premature Coronary Artery Disease patients. Those patients who had a history of angina, previous MI, infectious, autoimmune diseases, hyperlipidemia (familial), heart disease by birth, arthritis, diabetes mellitus, expectance of life $<12$ months along with those not giving informed or written consent were not included in the study. Moreover, 310 age and sex matched controls who were declared to be disease free on angiography were recruited. Any subject with acute or chronic ailment or taking anti-inflammatory drugs was not included in the control group. Expectant mothers or females taking contraceptives were excluded as well. General physical examination including detailed history and physical examination was done by a registered medical practitioner.

Ten ml blood sample was taken from the median cubital vein. Six ml blood was poured into a plain vacutainer tube to separate the serum. Four $\mathrm{ml}$ whole blood was poured into EDTA tube to extract genomic DNA using Gentra Puregene Blood kit (Qiagen, USA). Serum IL-18, TNF-alpha, IL-6 and IL-10 levels were measured using monoclonal antibodies on ELISA (Invitrogen). The cytokine SNPs rs187238 (IL-18), rs1800795 (IL-6), rs1800629 (TNF-alpha), rs1800871 (IL-10) and rs1946519 (IL-18) were genotyped using TAQMAN assays according to standard protocols and preformed primers. The reagent volumes for TAQMAN genotyping assays, per plate using TAQMAN buffer are shown in supplementary table-1(a). 
Table-3.5: Reagent Volumes for TAQMAN Genotyping assays, per plate using TAQMAN buffer.

\begin{tabular}{|ll|l|}
\hline \multicolumn{2}{|l|}{ Reagent } & Volume (ul) \\
TAQMAN $\quad$ Mastermix & (Life & 410 \\
technologies) & & \\
\hline Nuclease Free Water (Sigma) & $389.5 / 399.8$ \\
\hline 40x/80x SNP Specific Assay (Life & $20.5 / 10.3$ \\
Technologies) & & \\
\hline
\end{tabular}

The volume of SNP specific assay (which contains primers and probes) depends on whether it is supplied as 40 or $80 x$

The PCR conditions for TAQMAN genotyping assays are summarized in supplementary table-1(b).

Table-3.6:PCR conditions for TAQMAN Genotyping assays

\begin{tabular}{|l|l|}
\hline Temperature & Time \\
\hline $50^{0} \mathrm{C}$ & 2 mins \\
& \\
\hline
\end{tabular}




\begin{tabular}{|l|l|}
\hline $95^{\circ} \mathrm{C}$ & 10 mins \\
\hline $95^{\circ} \mathrm{C}$ & 15 sec $\mathrm{x} 40$ cycles \\
\hline $60^{\circ} \mathrm{C}$ & 1 min $\mathrm{x} 40$ cycles \\
\hline
\end{tabular}

The 5 cytokine gene promoter SNPs were selected from the meta-analyses (Smith et al., 2015) after a through literature search (Belsky et al., 2013). Details of SNPs selected for our study along with the respective references are shown in supplementary Table-2.

Table 3.2: Selected Cytokine SNPs

\begin{tabular}{|l|l|l|l|l|l|}
\hline Gene & SNP & $\begin{array}{l}\text { SNP } \\
\text { location }\end{array}$ & Risk Allele & Odds ratio & Reference \\
\hline$I L-18$ & $r s 187238$ & Promoter & $G$ & 1.12 & $\begin{array}{l}\text { Rajesh et } \\
\text { al.,2015 }\end{array}$ \\
\hline$I L-18$ & $r s 1956519$ & Promoter & $G$ & 1.24 & $\begin{array}{l}\text { Grisoni et } \\
\text { al.,2008 }\end{array}$ \\
\hline TNF-alpha & $r s 1800629$ & Promoter & $A$ & 1.13 & $\begin{array}{l}\text { Wang et } \\
\text { al.,2015 }\end{array}$ \\
\hline$I L-10$ & $r s 1800871$ & Promoter & $C$ & 1.44 & $\begin{array}{l}\text { Srikanth et } \\
\text { al.,2012 }\end{array}$ \\
\hline$I L-6$ & $R s 1800795$ & Promoter & $C$ & 1.11 & Hou et al.,2015 \\
\hline
\end{tabular}

TNF-alpha $=$ Tumor Necrosis Factor-alpha; IL-18=Interleukin-18; IL-10=Interleukin-10;IL$6=$ Interleukin -6 . 
Data analysis was done using standard SPSS software version-21 (SPSS Inc, Chicago, Illinois, USA) and R v3.0.3 (R Core Team, 2014). The allelic frequencies of all SNPs were checked for Hardy-Weinberg equilibrium (HWE) equation. Kolmogorov-Smirnov test of uniformity was applied on the data to assess its distribution. Mean \pm SD was calculated for continuous normally distributed (Gaussian distribution) variables. Continuous variables were compared amongst PCAD cases and controls using Independent t-tests. Categorical variables between PCAD cases and controls were compared using chi-square (X2- tests). Association between the gene polymorphisms and the serum cytokine levels were assessed by ANOVA and Post-hoc Tukey's test. A two-tailed p value $<0.05$ was taken as significant.

\section{RESULTS:}

The patients with PCAD had mean \pm SD age of $42 \pm 3.80$ years consisting of 329 males and 11 females. Demographic features are given in table-1.

Table-4.1: Baseline Characteristics of PCAD cases and controls $(n=650)$

\begin{tabular}{|l|l|l|l|}
\hline Parameters & $\begin{array}{l}\text { PCAD patients } \\
\text { n=340 } \\
\text { Mean } \pm \text { SD }\end{array}$ & $\begin{array}{l}\text { Controls } \\
\text { n=310 } \\
\text { Mean } \pm \text { SD }\end{array}$ & p-value \\
\hline Age (y) & $42 \pm 3.80$ & $39 \pm 7.8$ & \\
\hline Sex (m/f) & $329 / 11$ & $298 / 12$ & 0.12 \\
\hline Weight (kg) & $76.5 \pm 12.7^{*}$ & $69.0 \pm 11.8$ & 0.66 \\
\hline Height (m) & $1.7 \pm 0.12$ & $1.68 \pm 0.06$ & 0.303 \\
\hline $\begin{array}{l}\text { Ethnicity } \\
\text { Punjabis n(\%) }\end{array}$ & $\begin{array}{l}250(74 \%) \\
\text { Pathans n(\%) }\end{array}$ & $\begin{array}{l}193(62 \%) \\
117(38 \%)\end{array}$ & 0.301 \\
\hline BMI (kg/m2) & $26.6 \pm 6.7^{*}$ & $24.1 \pm 4.03$ & 0.22 \\
\hline $\begin{array}{l}\text { Diastolic BP (mm } \\
\text { Hg) }\end{array}$ & $83.0 \pm 9.6^{* *}$ & $73.1 \pm 3.8$ & 0.175 \\
\hline $\begin{array}{l}\text { Systolic BP (mm of } \\
\text { Hg) }\end{array}$ & $124.7 \pm 11.0^{* *}$ & $112.0 \pm 5.1$ & 0.0001 \\
\hline
\end{tabular}




\begin{tabular}{|l|c|l|l|}
\hline Smokers n (\%) & $197(58 \%)^{* *}$ & $81(26 \%)$ & $<0.01$ \\
\hline HTN self n (\%) & $163(48 \%)^{* *}$ & $34(11 \%)$ & $<0.01$ \\
\hline $\begin{array}{l}\text { Family history HTN } \\
\text { n(\%) }\end{array}$ & $136(40 \%)^{*}$ & $37(12 \%)$ & $<0.05$ \\
\hline $\begin{array}{l}\text { Family history } \\
\text { PCAD n(\%) }\end{array}$ & $112(33 \%)^{*}$ & $28(9 \%)$ & $<0.05$ \\
\hline $\begin{array}{l}\text { Family history DM } \\
\text { n(\%) }\end{array}$ & $78(23 \%)^{*}$ & $25(8 \%)$ & $<0.05$ \\
\hline $\begin{array}{l}\text { Family history IHD } \\
\text { ( } \%)\end{array}$ & $136(40 \%)^{* *}$ & $31(10 \%)$ & $<0.01$ \\
\hline $\begin{array}{l}\text { Total Cholesterol } \\
\text { (mmol/l) }\end{array}$ & $4.47 \pm 0.87^{*}$ & $4.2 \pm 0.77$ & 0.019 \\
\hline $\begin{array}{l}\text { Triglycerides } \\
\text { (mmol/l) }\end{array}$ & $2.4 \pm 1.15^{* *}$ & $1.9 \pm 0.73$ & 0.0001 \\
\hline $\begin{array}{l}\text { LDL-cholesterol } \\
\text { (mmol/l) }\end{array}$ & $2.32 \pm 0.77^{*}$ & $2.12 \pm 0.75$ & 0.043 \\
\hline $\begin{array}{l}\text { HDL-cholesterol } \\
\text { (mmol/l) }\end{array}$ & $1.07 \pm 0.23^{* *}$ & $1.24 \pm 0.25$ & 0.0001 \\
\hline $\begin{array}{l}\text { VLDL-cholesterol } \\
\text { (mmol/l) }\end{array}$ & $1.07 \pm 0.52^{* *}$ & $0.87 \pm 0.33$ & 0.001 \\
\hline
\end{tabular}

PCAD: Premature Coronary Artery Disease; DM: Diabetes Mellitus; HDL: High Density Lipoprotein; LDL: Low Density Lipoprotein; SD=Standard Deviation; CAD: Coronary Artery Disease; VLDL: Very Low Density Lipoprotein $* * \mathrm{p}<0.01 ; * \mathrm{p}<0.05$

Categorical variables were compared using a $\chi^{2}$ test while continuous variables were compared using independent t-tests.

Most of them were Punjabis $74 \%$ and only $26 \%$ were Pathans living in the Northern part of Pakistan. Body Mass Index (BMI), body weight, systolic \& diastolic blood pressure was significantly higher in PCAD patients compared to controls $(\mathrm{p}<0.05)$. The patients were mostly smokers with a positive family history of PCAD and hypertension $(\mathrm{p}<0.01)$. The genotypic distribution of the 5 cytokine SNPs namely IL-18 rs187238, IL-18 rs1946519, IL6 rs1800795, TNF-alpha rs1800629 and IL-10 r1800871 in PCAD patients and controls along with their odds ratios and risk allele frequencies are shown in Table- $2 \& 3$ respectively. 
Table-4.3: Genotypic distribution of the cytokine SNPs in PCAD cases $(n=340)$ and controls $(\mathbf{n}=310)$.

\begin{tabular}{|c|c|c|c|c|c|c|c|}
\hline Gene & $\begin{array}{l}\text { Genot } \\
\text { ypes }\end{array}$ & $\begin{array}{l}\text { Cases n } \\
(\%)\end{array}$ & $\begin{array}{l}\text { Alleles } \\
\text { n (\%) }\end{array}$ & $\begin{array}{l}\text { Controls } \\
\text { n (\%) }\end{array}$ & $\begin{array}{l}\text { Alleles } \\
\text { n }(\%)\end{array}$ & $\begin{array}{l}\text { Odds ratio } \\
\text { risk allele } \\
(95 \% \mathrm{CI})\end{array}$ & $\begin{array}{l}\text { p-value } \\
\text { HWE }\end{array}$ \\
\hline TNF-alpha & $A A$ & $10(3)$ & $\mathrm{G}=330(97)$ & $3(1)$ & $\mathrm{G}=307(99)$ & 1.47 & 0.12 \\
\hline rs 1800629 & $A G$ & 65 (19) & $* A=75 \quad(22)$ & $48(15)$ & $* A=51(16)$ & $(1.03-1.79)$ & \\
\hline$-308 G / A$ & $G G$ & $265(78)$ & & $259(84)$ & & & \\
\hline$I L-18$ & $G G$ & $194(57)$ & $* \mathrm{G}=302(89)$ & $152(51)$ & $* \mathrm{G}=267(86)$ & 1.13 & 0.11 \\
\hline$r s 1946519$ & $G T$ & $108(32)$ & $\mathrm{T}=145(42)$ & $115(36)$ & $\mathrm{T}=157(51 \%)$ & $(0.91-1.43)$ & \\
\hline$-656 G / T$ & $T T$ & $38(11)$ & & $43(13)$ & & & \\
\hline$I L-18$ & $G G$ & 217 (64) & ${ }^{*} \mathrm{G}=334(98)$ & $183(57)$ & $* \mathrm{G}=293(95)$ & 1.13 & 0.09 \\
\hline rs 187238 & $G C$ & $116(34)$ & $\mathrm{C}=123(36)$ & $108(37)$ & $\mathrm{C}=127(41)$ & $(1.01-1.43)$ & \\
\hline$-137 G / C$ & $C C$ & $7(2)$ & & $19(6)$ & & & \\
\hline$I L-6$ & $C C$ & $13(4)$ & $* \mathrm{C}=98(29)$ & $3(1)$ & $* \mathrm{C}=74(23)$ & 1.32 & 0.59 \\
\hline rs 1800795 & $G C$ & 85 (25) & $\mathrm{G}=326(96)$ & $71(22)$ & $\mathrm{G}=307(98)$ & $(1.12-1.55)$ & \\
\hline$-174 G / C$ & $G G$ & $242(71)$ & & $236(77)$ & & & \\
\hline$I L-10$ & $T T$ & $167(51)$ & $* \mathrm{C}=173$ (51) & $162(49)$ & ${ }^{*} \mathrm{C}=148(48)$ & 1.16 & 0.23 \\
\hline rs 1800871 & $C T$ & 119 (37) & $\mathrm{T}=286(84)$ & $110(35)$ & $\mathrm{T}=272(88)$ & $(0.81-1.55)$ & \\
\hline$-819 C / T$ & $C C$ & $54(12)$ & & $38(16)$ & & & \\
\hline
\end{tabular}

TNF-alpha $=$ Tumor Necrosis Factor-alpha; $\mathrm{CI}=$ Confidence Interval. IL-10=Interleukin10;IL-6= Interleukin-6; HWE=Hardy-Weinberg Equilibrium;IL-18=Interleukin-18; $\%=$ percentage; ${ }^{*} \mathrm{p}<0.05$ by applying Chi-Square test;

*=Risk allele 
Table 4.4: Computation of Cytokine SNPs Risk allele Frequencies between PCAD cases $(n=340)$ and controls $(n=310)$.

\begin{tabular}{|c|c|c|c|c|c|}
\hline Gene & rs number & $\begin{array}{l}\text { Cases } \\
\text { RAF }(95 \% \text { CI })\end{array}$ & $\begin{array}{l}\text { Controls } \\
\text { RAF (95\% CI) }\end{array}$ & $\begin{array}{l}\text { Risk } \\
\text { Allele }\end{array}$ & p-value \\
\hline $\begin{array}{l}\text { TNF- } \\
\text { alpha } \\
-308 \text { G/A }\end{array}$ & rs1800629 & $0.11(0.09-0.14)$ & $0.08(0.06-0.11)$ & $\mathrm{A}$ & 0.07 \\
\hline $\begin{array}{l}I L-18 \\
-656 G / T\end{array}$ & $r s 1946519$ & $0.73(0.70-0.76)$ & $0.68(0.64-0.71)$ & $\mathrm{G}$ & 0.11 \\
\hline $\begin{array}{l}I L-18 \\
-137 G / C\end{array}$ & $r s 187238$ & $0.81(0.78-0.84)$ & $0.76(0.73-0.83)$ & $\mathrm{G}$ & $0.015^{*}$ \\
\hline $\begin{array}{l}I L-6 \\
-174 G / C\end{array}$ & $r s 1800795$ & $0.16(0.14-0.19)$ & $0.12(0.10-0.15)$ & $\mathrm{C}$ & $0.021 *$ \\
\hline $\begin{array}{l}I L-10 \\
-819 C / T\end{array}$ & $r s 1800871$ & $0.70(0.63-0.70)$ & $0.66(0.66-0.74)$ & $\mathrm{C}$ & 0.19 \\
\hline
\end{tabular}

IL-10=Interleukin-10;IL-6= Interleukin-6; RAF=Risk Allele Frequency; IL18=Interleukin-18; CI=Confidence Interval; TNF-alpha= Tumor Necrosis Factor-alpha; $* \mathrm{p}<0.05$ by applying Chi-Square test

Among the cytokine SNPs TNF-alpha rs1800629 and IL-6 rs1800795 has the highest odds ratio for the risk prediction of PCAD. All the cytokine SNPs complied with Hardy-Weinberg equilibrium. The risk allele frequencies of IL-6 (rs1800795) and IL-18 (rs187238) were significantly higher in the PCAD cases compared to the disease free controls $(\mathrm{p}<0.05)$. 
IL-18 levels in serum were significantly greater in the IL-18 rs 187238 GG genotype as compared to GC \& CC genotypes ( $p<0.05)$. Mean \pm SD values of serum IL-18 levels were $277.1 \pm 4.63,257.9 \pm 7.57$ and $217.8 \pm 7.68 \mathrm{pg} / \mathrm{ml}$ in $\mathrm{GG}, \mathrm{GC}$ and $\mathrm{CC}$ genotypes respectively. Interestingly serum IL-10 level was also significantly greater in the GG homozygotes as compared to the GC and CC genotypes $(\mathrm{p}<0.05)$. Mean \pm SD values of IL10 levels were $0.88 \pm 0.07,0.85 \pm 0.12$ and $0.81 \pm 0.12$ in GG, GC and CC genotypes respectively. Comparison of serum IL-18 \& IL-10 cytokine levels with respect to the genotypic distribution of $I L-18$ rs 187238 SNP is shown in Fig-1 (a).

Serum IL-18, TNF-alpha and serum IL-6 levels were significantly higher in the IL-18 rs 1946519 GG genotype patients as compared to GT and TT genotypes $(\mathrm{p}<0.05)$. Interestingly the serum IL-18:IL-10 and TNF-alpha:IL-10 ratios were significantly higher in GG genotype patients as compared to GT and TT genotypes $(\mathrm{p}<0.01)$. The comparison of serum IL-18, TNF-alpha, IL-6, IL-18:IL-10 and TNF-alpha:IL-10 ratios with respect to the genotypic distribution of IL-18 rs 1946519 SNP is shown in Fig-1 (b). Detailed serum IL-18, TNF-alpha, IL-6, IL-18:IL-10 and TNF-alpha:IL-10 ratios with respect to the genotypic distribution of $I L-18$ rs1946519 SNP are shown in supplementary table-3.

There was no significant difference in the serum IL-18, IL-6, TNF-alpha, IL-10, IL-18/IL10 and TNF-alpha:IL-10 ratios with respect to the genotypic distribution of $I L-10$ rs 1800871 SNP in the PCAD patients ( $p>0.05$ ). Serum IL-18 and IL-6 levels were significantly higher in patients having the $I L-6$ rs 1800795 CC genotype as compared to GC and GG genotypes $(\mathrm{p}<0.05)$. Mean \pm SE values of serum IL-18 levels were $283.4 \pm 31.1,274 \pm 30.3$ and 262.4 $\pm 19.93 \mathrm{pg} / \mathrm{ml}$ while serum IL-6 levels were $3.8 \pm 1.0,2.9 \pm 0.64$ and $1.4 \pm 0.60 \mathrm{ng} / \mathrm{dl}$ in CC, 
GC and GG genotypes respectively. Comparison of serum IL-18 and IL-6 cytokine levels with respect to the genotypic distribution of $I L-6$ rs 1800795 SNP is shown in Fig-1 (c).

Serum IL-18, IL-18:IL-10 and TNF-alpha:IL-10 ratios were significantly higher in the TNF-alpha rs1800629 A-allele homozygotes as compared to GA and GG genotypes ( $<<0.05)$ as shown in fig-1(d). IL-18 SNP rs1946519 had the maximum influence on the serum cytokine levels by significantly altering IL-18, TNF-alpha, IL-6, IL-18:IL-10 and TNFalpha:IL-10 ratio levels followed by TNF-alpha SNP rs 1800629 which significantly altered the serum levels of IL-18, IL-18:IL-0 and TNF-alpha:IL-10 ratios.

\section{DISCUSSION:}

The risk allele of IL-18 rs187238 and IL-18 rs1946519 SNPs in our population was $\mathrm{G}$ based on odds ratio of the allele for PCAD. This is in agreement with a study carried out on South Asian population by Kumar et al., 2015. The risk allele frequencies of the above mentioned SNPs were significantly raised in the PCAD cases as compared to the disease free controls. While some studies support the results of our study showing significant association of the IL-18 rs187238 and IL-18 rs1946519 SNPs with CAD (Hernesniemi et al., 2010) others have shown no such association (Shayan et al., 2007). A study done on Brazilian patients has also not shown any association of these SNPs with the cardiovascular risk factors (Farias et al., 2013). Genotypic distribution of the IL-6 rs 1800795 SNP was also determined in our study subjects. The risk allele for IL-6 rs 1800795 our study was C. This is in agreement with another study carried out in the high risk Pakistani families where the minor allele C showed high prevalence in cases compared to controls (Satti et al., 2013). As far as the risk allele frequency of the IL-6 rs1800795 SNP and its association with CAD is concerned the results in different population remained discrepant. While a strong association of the risk 
allele $\mathrm{C}$ was demonstrated with CAD in the Chinese (Hou et al., 2015) and Indians (Bhanushali et al.,2013) no such association was seen in the Tunisians (Ghazouani et al.,2011). The Northwick Park Heart study on the other hand showed that the IL-6 rs 1800795 GC (heterozygotes) were significantly at a greater risk to develop CAD as compared to the CC homozygotes (Humphries et al.,2001).

The risk allele for TNF-alpha rs1800629 was A in our study group. However, the risk allele frequency of TNF-alpha rs1800629 did not vary significantly between the PCAD patients and controls. The observation in our study conflicts with the results seen in a recent study carried out to see the association of TNF-alpha rs1800629 SNP with familial CAD (Hussain et al.,2015) and another study on Italian subjects (Szalai et al.,2002) and Indians (Bhanushali et al.,2013). However, it agrees with some studies where there was no association between the TNF-alpha rs1800629 SNP and CAD outcomes (Elahi et al.,2009) neither was there any variation in the risk effects of the TNF-alpha rs1800629 SNP between Caucasians and Asians (Chu et al.,2012).

The risk allele in IL-10 rs1800871 SNP was C in our study subjects however the RAF did not differ significantly between PCAD cases and controls. The risk allele in the Chinese Han population on the other hand was identified as T for the IL-10 rs1800871 SNP (Yong et al., 2015) and it showed strong significant association with valvular calcification. The risk allele frequency of IL-10 rs1800871 was not raised significantly in the PCAD cases as compared to disease free controls in our study. This conflicts with the observations in a study carried out on CAD patients by Afzal et al., 2012 where the allele frequency of the protective allele $\mathrm{T}$ was significantly raised in the controls as compared to the cases. However, our results 
are in agreement with the study conducted by Koch et al., 2001 where the IL-10 polymorphisms did not associate significantly with the risk of CAD.

The cause of these inter-ethnic variations is not definitively known as yet but some of the probable reasons of difference in the association of SNPs with a disease trait are allele frequency differences among ethnicities and variable patterns of linkage disequilibrium resulting in 'tag SNPs' which differ by population strata (Smith et al., 2015). These observations form a strong basis of the impact of ethnic descent and deviation from the HWE on the variable distribution of cytokine gene promoter SNPs in PCAD. Knowledge of these cytokine allele frequencies in our Pakistani subjects is essential because they may be a major contributing factor towards racial disparities with respect to the mortality and morbidity of low grade inflammatory disease like PCAD (VanDyke et al., 2009).

Serum cytokines are in part a heritable trait (Matteini et al., 2014). To the best of our knowledge this is the first comprehensive study which has demonstrated the effect of the pro-inflammatory and anti-inflammatory cytokine gene variants on the serum cytokine levels with respect to the risk allele distribution. The serum IL-18 level was significantly raised in the GG genotype of the IL-18 rs187238 SNP in PCAD patients in our study as compared to the GC and CC genotypes. This observation is supported by another study which supports the role of IL-18 rs187238 SNP in variable expression of IL-18 (Tiret et al.,2005).Contrary to this it was reported in a previous study that IL-18 levels were not influenced by the IL-18 rs187238 genotypes (Opstad et al.,2011). The conflicting results point to the need of identification of the actual causal variants in the IL-18 gene. Interestingly, serum IL-10 was raised significantly in the risk allele homozygotes GG suggesting that the IL-18 rs $187238 \mathrm{G}$ allele probably has an effect on the enhancers regulating the transcription of the IL-10 gene 
promoter region leading to the increase in the anti-inflammatory cytokine production to counter the inflammatory response. The IL-18 rs1946519 SNP GG genotype was significantly associated with higher pro-inflammatory cytokine levels (IL-18, TNF-alpha and IL-6) and cytokine imbalance. This cytokine imbalance and greater susceptibility to the disease is probably because of the simultaneous action of the IL-18 rs1946519 gene variant on the transcription regulation factors of the pro- and anti-inflammatory cytokines mainly by promoting binding of the nuclear factors to transcription regulatory sites of these cytokines leading to variable mRNA expression. Our observation is supported by a study which states that a single enhancer or silencer can regulate multiple genes at a time (Mohrs et al., 2009).

The IL-10 serum levels were not significantly different in the risk allele carriers of the IL-10 rs1800871 SNP as compared to the non-carriers in our study. On the contrary a study shows that IL-10 levels are influenced by IL-10 gene variants including rs1800871 SNP (Jose Carlos et al., 2015). A possible explanation for this difference might be that the IL-10 rs1800871 might not be the functional variant and might just be in close proximity or in linkage disequilibrium with the functional variant. The $I L$ - 10 gene 5 '-flanking sequence has three SNPs upstream from the transcriptional start site, at positions -1082 (G/A: rs1800896), $-819(\mathrm{C} / \mathrm{T})$, and -592 (C/A: rs1800872), that regulate IL10 expression and they all are in strong LD (Maziad et al., 2010) making it difficult to identify the exact locus that is most influencing the serum levels of IL-10. Another probable explanation could be the suppression of IL-10 production via activation of the STAT group of transcription regulation factors (repressors) by the IL-10 gene variant (Kahraman et al., 2006). More detailed functional studies including haplotype analyses with denser SNP panels and direct 
sequencing will be required to localize the causal variants in this region to unravel the exact mechanism.

IL-6 rs1800795 SNP significantly affected the serum IL-18 and IL-6 levels as they were higher in the risk allele C carriers of this SNP. Since this is a promoter region polymorphism certain researchers suggest that it might directly affect at the transcription regulation factors (activators) leading to altered production of IL-6 (Satti et al.,2013) or that it might be tagging a gene variant affecting the transcriptional regulation of IL-18 production (Matteini et al., 2014). Some studies suggest that the IL-6 rs1800795 SNP might be altering the methylation levels of the IL-6 gene promoter (Yang et al., 2012). The transcriptional silencing occurs as a result of hypermethylation of gene promoters while overexpression is a result of DNA hypomethylation. Previous studies have shown that various inflammatory cytokines are regulated via epigenetic mechanisms in human cancers (Tekpli et al., 2013) however, till today, the information regarding the epigenetic mechanisms regulating cytokines in PCAD is scarce and needs due attention.

The risk allele A carriers of TNF-alpha rs1800629 did not have significantly higher levels of serum TNF-alpha in PCAD patients as compared to the non-carriers in our study. A probable reason for this is that a study demonstrates that three genetic variants in the gene promoter of TNF-alpha gene act synergistically to determine the functioning of the TNFalpha gene (Cui et al., 2012). Certain studies show that the A allele of TNF-alpha rs1800629 does not affect TNF-alpha gene transcription (Elahi et al., 2009). There have been conflicting results regarding the risk allele of TNF-alpha rs1800629 also as some studies have shown the higher TNF-alpha production from G/A heterozygotes and GG homozygotes. Therefore, there is a possibility that the TNF-alpha production might be under the influence of 
multifactorial regulatory process. On the other hand serum IL-18, IL-18:IL-10 and TNFalpha:IL-10 ratios were significantly higher in the $\mathrm{G}$ allele carriers of TNF-alpha rs1800629 SNP. A probable explanation could be that the SNP is in close proximity to or tagging a SNP affecting the transcription binding activity in the IL-18, TNF-alpha \& IL-10 gene promoter regions enhancing the production of IL-18 and repressing production of IL-10 causing pro.anti-inflammatory imbalance in PCAD. Cytokine polymorphisms have been shown to influence transcription, translation and levels of proteins in the atherosclerotic plaque (Cappuccilli et al., 2014). Our study has shown that inherited genetic variations in cytokine genes can affect the phenotypic traits like inflammatory biomarker levels in PCAD which can become the therapeutic targets in future. The serum cytokine levels did not vary significantly with respect to the genotypic distribution of the 5 cytokine gene promoter SNPs in the disease free controls of our study.

\section{CONCLUSIONS:}

The cytokine gene promoter SNPs (genotypic trait) have significant influence on the serum cytokine levels and the pro-/anti-inflammatory cytokine imbalance (phenotypic trait) which makes them making them important therapeutic and epipeutic targets in PCAD patients.

ACKNOWLEDGEMENTS: We wish to acknowledge the efforts of all the laboratory technicians who participated in the study. My sincere gratitude to my fellow researcher Miss Katherine Beaney and my colleague Miss Li Kawah at CVG for their valuable guidance, suggestions and input.

\section{COMPETING INTERESTS: NONE}


FUNDING: This study was funded by the International Research Support Initiative Program of Pakistan under the auspices of the Higher Education Commission of Pakistan. SEH is a British Heart Foundation (BHF) Professor and he is funded by a BHF grant (BHFPG08/008) and by the National Institute for Health Research UCL Hospitals Biomedical Research Centre. 


\section{REFERENCES:}

Dhillon, T., Niranjan, S., Khanna, A. et al.(2004) Premature Coronary Artery Disease $[C A D]$ in the Asian Immigrant Population: Data from a New York City Hospital. Chest J.,126(4):790S.

Rosamond, W., Flegal, K., Friday, G.( 2007). Heart disease and stroke statistics--2007 update: a report from the American Heart Association Statistics Committee and Stroke Statistics Subcommittee. Circulation.,115 (5): e69-171.

Aggarwal, A., Aggarwal, S. \& Sharma, V. (2014). Predisposing Factors to Premature Coronary Artery Disease in Young (Age $\leq 45$ Years) Smokers: A Single Center Retrospective Case Control Study from India. J Cardiovasc Thorac Res;6(1), 15-19

Kaptoge, S., Seshasai, S.R., Gao, P., Freitag, D.F., Butterworth, A.S., Borglykke, A., Di Angelantonio, E., Gudnason, V., Rumley, A., Lowe, G.D., Jørgensen, T., Danesh, J.(2014). Inflammatory cytokines and risk of coronary heart disease: new prospective study and updated meta-analysis. Eur Heart J.;35(9):578-89. $\quad$ doi: 10.1093/eurheartj/eht367. Epub 2013 Sep 10.

Khan, M.A., Hassan, M., Hafizullah, M.(2006). Coronary Artery Disease, is it more frequently effecting younger age group and women? Pakistan Heart Journal.,39(1-2):11-14.

Autieri, M.V.(2012). Pro- and Anti-Inflammatory Cytokine Networks in Atherosclerosis. ISRN Vascular Medicine ; Article ID 987629, 17 pages 
XiaoFeng,Z., HongLi,L.(2009). Research progress on interleukin-18, interleukin-10, interleukin-18/interleukin-10 ratio and the vulnerability in coronary atherosclerosis plaques. Progress in Modern Biomedicine.,9(22):4387-4389.

Wojciech,K., Roksolana,D., Monika,P.K., Alina,O., Walentyna,M.(2008). Plasma levels of TNF-[alpha], IL-6, and IL-10 and their relationship with left ventricular diastolic function in patients with stable angina pectoris and preserved left ventricular systolic performance. Pathophysiology and Natural History.,19(6):375-382.

Satti, H.S., Hussain, S., and Javed, Q.(2013). Association of Interleukin-6 Gene Promoter Polymorphism with Coronary Artery Disease in Pakistani Families The Scientific World Journal.Article ID 538365, 6 pages.

Choi, C.U., Seo, H.S., Lee, E.M., Shin, S.Y., Choi, U.J., Na, J.O., Lim, H.E., $\quad$ Kim, J.W., Kim, E.J., Rha, S.W., Park, C.G., and Oh, D.J.(2010). Statins Do Not Decrease Small, Dense Low-Density Lipoprotein.Tex Heart Inst J.; 37(4): 421-428.

Smith, J.A.,Ware, E.B., Middha, P., Beacher, L., Kardia, S.L.R.(2015). Current Applications of Genetic Risk Scores to Cardiovascular Outcomes and Subclinical Phenotypes .Current Epidemiology Reports; 2(3):180-190

Belsky, D.W., Moffitt, T.E., Sugden, K., et al (2013). Development and evaluation of a genetic risk score for obesity. Biodemography Soc Biol.;59(1):85-100.

Grisoni, M.L., Proust, C., Alanne, M., DeSuremain, M., Salomaa, V., Kuulasmaa, K., Cambien, F., Nicaud, V., Stegmayr, B., Virtamo, J., Shields, D., Kee, F., Tiret, $\quad$ L., Evans, A., and Tregouet, D.A.(2008). Haplotypic analysis of tag SNPs of the interleukin-18 
gene in relation to cardiovascular disease events: the MORGAM Project European Journal of Human Genetics;16, 1512-1520; doi:10.1038/ejhg.2008.127.

Wang, A.Z., Li, L., Zhang, B., Shen, G.Q., Wang, Q.K.(2011). Association of SNP rs17465637 on chromosome $1 \mathrm{q} 41$ and rs599839 on 1p13.3 with myocardial infarction in an American Caucasian population. Ann Hum Genet. ;75(4):475- 82. doi: 10.1111/j.1469-1809.2011.00646.x. Epub 2011 Apr 4.

Hou, H., Wang, C., Sun, F., Zhao, L., Dun, A., Sun, Z.(2015). Association of interleukin- 6 gene polymorphism with coronary artery disease: an updated systematic review and cumulative meta-analysis. Inflamm Res.; 64(9):707-20. doi: 10.1007/s00011-0150850-9.

Kumar, J., Yumnam, S., Basu, T., Ghosh, A., Garg, G., Karthikeyan, G., Sengupta, S.(2011). Association of polymorphisms in 9p21 region with CAD in North Indian population: replication of SNPs identified through GWAS. Clin Genet.;79(6):588-93. doi: 10.1111/j.1399-0004.2010.01509.x.

Satti, H.S., Hussain, S., and Javed, Q.(2013). Association of Interleukin-6 Gene Promoter Polymorphism with Coronary Artery Disease in Pakistani Families. The Scientific World Journal; Article ID 538365, 6 pages.

Hou, H., Wang, C., Sun, F., Zhao, L., Dun, A., Sun, Z.(2015). Association of interleukin- 6 gene polymorphism with coronary artery disease: an updated systematic review and cumulative meta-analysis. Inflamm Res.; 64(9):707-20. doi: 10.1007/s00011-0150850-9. 
Bhanushali, A.A., and Das, B.R.(2013). Promoter variants in interleukin-6 and tumor necrosis factor alpha and risk of coronary artery disease in a population from Western India.Indian J Hum Genet.; 19(4): 430-436. doi: 10.4103/09716866.124371

Gaziano, T.A., Bitton, A., Anand, S., Abrahams-Gessel, S., and Murphy, A.(2010). Growing Epidemic of Coronary Heart Disease in Low- and Middle-Income Countries.Curr Probl Cardiol.; 35(2): 72-115. doi: $\quad$ 10.1016/j.cpcardiol.2009.10.002

Global status report on noncommunicable diseases 2010 .WHO headquarters, 2010

\section{FIGURE LEGENDS:}

Fig-1 (a) Bar chart showing comparison of serum IL-18 and IL-10 cytokine levels with respect to the genotypic distribution of $I L-18$ rs 187238 SNP by applying One-way ANOVA analysis and Post Hoc Tukey's test.

Fig-1 (b) Bar chart showing comparison of serum IL-18, TNF-alpha, IL-6, IL-18/IL-10 and TNF-alpha/IL-10 ratios with respect to the genotypic distribution of $I L-18$ rs 1946519 SNP by applying One-way ANOVA analysis and Post Hoc Tukey's test.

Fig-1(c) Bar Chart showing comparison of serum IL-18 and IL-6 cytokine levels with respect to the genotypic distribution of $I L-6$ rs1800795 SNP by applying One-way ANOVA analysis and Post Hoc Tukey's test.

Fig-1(d) Bar chart showing comparison of serum IL-18, IL-18/IL-10 and TNF-alpha/IL10 ratios with respect to the genotypic distribution of TNF-alpha rs $1800629 \mathrm{SNP}$ by applying One-way ANOVA analysis and Post Hoc Tukey's test. 